\title{
A centralidade do valor na categoria de trabalho abstrato
}

\author{
Havana Maria Ribeiro Alves ${ }^{1}$ \\ https://orcid.org/0000-0003-0139-688X
}

\section{Leandro Nunes ${ }^{2}$}

https://orcid.org/0000-0002-1806-3013

\author{
Pablo Ramon Diogo ${ }^{3}$ \\ https://orcid.org/0000-0001-6493-0344
}

\author{
'Universidade Federal de Santa Catarina, Departamento de Serviço Social, Programa de Pós-graduação em Serviço Social, \\ Florianópolis, SC, Brasil \\ ${ }^{2}$ Universidade Federal de Santa Catarina, Departamento de Serviço Social, Programa de Pós-graduação em Serviço \\ Social, Florianópolis, SC, Brasil \\ ${ }^{3}$ Universidade Federal de Santa Catarina, Departamento de Serviço Social, Curso de Serviço Social, Florianópolis, SC, \\ Brasil
}

\section{A centralidade do valor na categoria de trabalho abstrato}

Resumo: O presente artigo, de teor fundamentalmente teórico, objetiva investigar a relação entre as categorias trabalho abstrato e valor. Para tanto, analisa as particularidades da lei do valor e do modo de produção capitalista, assim como busca compreender o significado do dinheiro enquanto equivalente universal. Esse artigo, de natureza qualitativa, apresenta duas partes inter-relacionadas expostas em forma de itens e realizou-se mediante pesquisa bibliográfica, consistindo na exposição dos pressupostos analíticos que subsidiam a apreensão do problema de pesquisa.

Palavras-chave: Trabalho Abstrato; Valor; Mercadoria; Modo de produção capitalista

\section{The centrality of value in the abstract labour category}

Abstract: This article, which is fundamentally theoretical, aims to investigate the interaction between the categories abstract labour and value. In that matter, it analyzes the particularities of the law of value and the capitalist mode of production, as well as understanding the meaning of money as a universal equivalent. This article, of a qualitative nature, presents two interrelated parts exposed in the form of items and was carried out through bibliographic research, consisting of the exposition of the analytical assumptions that support the apprehension of the research problem.

Keywords: Abstract Labour; Value; Commodity; Capitalist mode of production.

Recebido em: 25.05.2021. Aprovado em: 31.08.2021. Revisado em: 03.09.2021. comerciais e que o trabalho original seja corretamente citado. 


\section{Introdução}

A centralidade do valor no modo de produção capitalista compreende suas formas de manifestação na realidade humano-social, inferindo nela um caráter particular como condição de existência e produção da forma-mercadoria. A questão que se coloca enquanto modo de produção predominante, como produtor de mercadoria e capital, é a troca de mercadorias, pois esta aparece como a forma elementar da riqueza das sociedades ${ }^{1}$.

Com essa projeção o presente artigo investiga a relação entre as categorias trabalho abstrato e valor. Nesse sentido, as principais inquietações que perpassaram o estudo são: qual a relação entre as categorias trabalho abstrato e valor? Qual o significado do dinheiro enquanto equivalente universal?

$\mathrm{O}$ fio condutor de resposta aos questionamentos anteriormente apresentados deu-se a partir do objetivo anteriormente citado: compreender a relação entre as categorias trabalho abstrato e valor. Desse objetivo desdobram-se outros dois, são eles: (a) apresentar as particularidades da lei do valor, e; (b) compreender o significado do dinheiro enquanto equivalente universal e sua manifestação.

Nesse sentido, de maneira a responder a nosso problema de pesquisa e contemplar os objetivos propostos, definiu-se a utilização do método dialético, que pressupõe uma revisão e reflexão crítica do objeto de estudo. Como procedimento metodológico utilizou-se a pesquisa bibliográfica² ${ }^{2}$.

Considerando que as categorias de análise se articulam dialeticamente, a exposição categorial do estudo apresenta-se em dois momentos inter-relacionados, expostos nos seguintes itens: (1) mercadoria e valor: considerações preliminares; (2) o valor enquanto troca equivalente: a manifestação do trabalho abstrato. Vamos a eles!

\section{Mercadoria e valor: considerações preliminares}

Marx compreende as sociedades que se estruturam no modo de produção capitalista como uma "enorme coleção de mercadorias" em que a mercadoria individual "aparece como sua forma elementar" (MARX, 2017a, p. 113). A troca de mercadorias, que de maneira mais acabada se expressará na grandeza de valor, isto é, no quantum de trabalho necessário para a produção da mercadoria, é o cerne do processo de valorização.

Mesmo que as mercadorias por si não representem valor, mas sim sua utilidade, seus valores de uso relacionando-se com outras mercadorias precisam exprimir outra forma além da utilidade - que será representado em seu valor. Nesse sentido "[...] na objetividade de seu valor não está contido um único átomo de matéria natural [Naturstoff]. Por isso, pode-se virar e revirar uma mercadoria como se queira, e ela permanece inapreensível como coisa de valor [Wertding]" (MARX, 2017a, p. 125).

Aqui habita a determinação geral das mercadorias - enquanto não apenas objeto, mas sujeito do modo de produção capitalista - que só se exterioriza de modo dialético, a saber: seu valor e valor de uso, ou seja, sua grandeza e seu caráter de atender às necessidades especificamente humanas ${ }^{3}$. Portanto, a troca de mercadorias irá se explicitar mais concretamente em seu valor, pois este consegue representar uma grandeza mensurável de troca de forma quantitativa e não apenas enquanto um fator puramente qualitativo, como natureza comum de todas as mercadorias que se representa em seu valor de uso. A troca de mercadorias, então, é o momento central da esfera da circulação, a qual pressupõe a produção de mercadorias centralizada no valor, na produção de valores.

Aqui a relação entre valor e valor de uso toma uma peculiaridade intrínseca, pois, o valor enquanto grandeza só consegue se objetivar ou se materializar num corpo útil, numa mercadoria que contenha valor de uso. Por isso, a mercadoria é, também, substância de valor que se manifesta em seu valor de uso, sendo o valor apenas sua forma de expressão enquanto medida de grandeza ${ }^{4}$. Desta forma, a produção de mercadorias é ponto importante para a circulação e a efetivação do valor que contenha essa mercadoria, que ocorre por meio da troca.

$\mathrm{Na}$ esfera da produção, o determinante é a atuação do valor, que só consegue se objetivar por meio do processo de trabalho. $\mathrm{O}$ processo de trabalho, enquanto reflexo do trabalho concreto, é uma condição especificamente humana da existência, reprodução e transformação. Conforme aponta Lukács: 
[...] a essência do trabalho humano consiste no fato de que, em primeiro lugar, ele nasce em meio à luta pela existência e, em segundo lugar, todos os seus estágios são produtos de sua autoatividade. [...] Somente o trabalho tem, como sua essência ontológica, um claro caráter de transição: ele é, essencialmente, uma inter-relação entre homem (sociedade) e natureza, tanto inorgânica (ferramenta, matéria-prima, objeto de trabalho etc.) como orgânica [...], mas antes de tudo, assinala a transição, no homem que trabalha, do ser meramente biológico ao ser social. (LUKÁCS, 2013, p.43-44, grifo nosso).

Contudo, o ser social que trabalha no modo de produção capitalista o faz enquanto trabalhador assalariado, enquanto força de trabalho ${ }^{5}$ que precisa vender-se no mercado em troca de salário. Desse modo, cumpre salientar, que sob o modo capitalista de produção, o trabalho assalariado, isto é, a venda da força de trabalho, se diferencia do trabalho nas sociedades pré-capitalistas, seja em relação ao seu próprio trabalho, seja em relação ao produto de seu trabalho. Nesse sentido, se ao longo do regime feudal havia uma relação em que o servo laborava nas terras do senhor feudal para produzir a satisfação de suas necessidades, entregando-o parte de sua produção, agora, ele labora nas fábricas, nas terras, etc. em troca de um quantum monetário que deveria ser suficiente para a compra de insumos, a fim de satisfazer suas necessidades. Marx $(2014,2017 \mathrm{~b})$ destaca esse processo como parte constitutiva da "coisificação", em que a força de trabalho passa a dotar de um quantum monetário, é o que abre pressupostos para a exploração e alienação do trabalhador, bem como da sua força de trabalho.

Assim sendo, questiona-se: qual o valor da força de trabalho? Junto as exposições do autor citado, destaca-se que assim como qualquer outra mercadoria no modo de produção capitalista, o valor da força de trabalho também o é determinado pelo tempo de trabalho socialmente necessário para a sua produção, bem como, para a sua reprodução (MARX, 2017a, p. 243). Desse modo, se o trabalhador labora durante uma jornada de trabalho $\mathrm{X}$ em troca de um salário Y visando a compra de mercadorias para a satisfação de suas necessidades, o valor da força de trabalho não é senão "[...] o valor dos meios de subsistência necessários à manutenção de seu possuidor" (MARX, 2017a, p. 243). Ainda, em relação aos salários, eles podem se dar basicamente de duas formas: a) por tempo, ou seja, diário, semanal ou mensal, sendo este o mais comum, a exemplo, o setor de serviços, construção civil, entre outros, e; b) por peça/produção, este que tem crescido nos últimos anos, a exemplo de alguns setores da construção civil, nos portos, comércio, etc.

A força de trabalho é, aparentemente, uma mercadoria como as demais - uma vez que compartilha das características comum à todas as outras mercadorias - e diferente das demais, pois, como mercadoria especial, ao ser utilizada pelo capitalista, restitui o valor representado pelo salário, acrescido de um adicional de valor: o mais-valor. Este último, sendo apropriado privadamente apenas pelo capitalista. Nesse sentido, é pela produção do mais-valor que ocorre o processo de valorização do valor. A venda da força de trabalho e a relação capitalista de produção infere uma metamorfose no mundo dos homens, pois:

[...] as mesmas circunstâncias que produzem a condição fundamental da produção capitalista - a existência de uma classe de trabalhadores assalariados - exigem que toda produção de mercadorias se transforme em produção capitalista de mercadorias. À medida que esta última se desenvolve, ela exerce um efeito destrutivo e dissolvente sobre todas as formas anteriores de produção, que, voltadas preferencialmente à satisfação das necessidades imediatas do produtor, só convertem em mercadoria as sobras do que foi produzido. Ela faz da venda do produto o interesse primordial, sem que, de início, isso pareça afetar o próprio modo de produção, o que, por exemplo, constituiu o primeiro efeito do comércio capitalista mundial sobre povos como o chinês, o indiano, o árabe etc. Em segundo lugar, porém, onde lança raízes, ela destrói todas as formas da produção de mercadorias baseadas seja no trabalho dos próprios produtores, seja meramente na venda dos produtos excedentes como mercadorias. Primeiramente ela universaliza a produção de mercadorias e, então, transforma gradualmente toda a produção de mercadorias em produção capitalista. (MARX, 2014, p. 118, grifo nosso).

Nas assinalações dadas por Marx, a transformação que o modo capitalista de produção ocasiona se dá ao passo que se apodera do desenvolvimento das forças produtivas em cada momento histórico-econômico, e ele o faz, pois:

Sua tendência é converter toda a produção possível em produção de mercadorias; para tanto, seu meio principal é justamente essa incorporação da produção em seu processo de circulação; e a produção de 
mercadorias, quando atinge seu estágio desenvolvido, é produção capitalista de mercadorias. A intervenção do capital industrial estimula por toda parte essa transformação, mas, com ela, também a transformação de todos os produtores diretos em trabalhadores assalariados. (MARX, 2014, p. 189).

Vemos assim, que a determinação essencial da produção é a produção capitalista de mercadorias colocada sob a égide do trabalho assalariado, pois somente nessa relação de classes entre capitalista e trabalhador assalariado (um representando a personificação do capital e outro a do trabalho, respectivamente) é que poderse-ia dar a produção de mais-valor, que converte todo o processo de trabalho, essencialmente, em processo de valorização. O que sucede desse processo é a constante tentativa de valorização do valor, alicerçada na troca de mercadorias. Portanto, o modo de produção capitalista tem uma lógica intrínseca de mercantilizar todo a atividade humana em prol do capital ${ }^{6}$. A busca do valor se estabelece numa relação social, em que o trabalhador enquanto mercadoria, precisa alienar seu valor de uso para receber seu valor, isto é, seu salário. Uma vez que sua força de trabalho:

Se não é vendida, ela não serve de nada para o trabalhador, que passa a ver como uma cruel necessidade natural o fato de que a produção de sua capacidade de trabalho requer uma quantidade determinada de meios de subsistência, quantidade que tem de ser sempre renovada para sua reprodução. [...] Da natureza peculiar dessa mercadoria específica, a força de trabalho, resulta que, com a conclusão do contrato entre comprador e vendedor, seu valor de uso ainda não tenha passado efetivamente às mãos do comprador. Seu valor, como o de qualquer outra mercadoria, estava fixado antes de ela entrar em circulação, pois uma determinada quantidade de trabalho social foi gasta na produção da força de trabalho, porém seu valor de uso consiste apenas na exteriorização posterior dessa força. Por essa razão, a alienação da força e sua exteriorização efetiva, isto é, sua existência como valor de uso, são separadas por um intervalo de tempo (MARX, 2017a, p. 248).

A transformação operada no mundo do trabalho é a forma de enquadramento necessária para a produção e reprodução capitalista, enquanto na mercadoria força de trabalho seu valor é concebido pela forma-salário, isto é, a forma que se manifesta o valor da força de trabalho nas relações em que predomina a forma-mercadoria, e seu valor de uso reside na capacidade de valorização do valor, ou seja, na produção de mais-valor. Por isso têm-se uma importância primordial a categoria de trabalho abstrato na Crítica da Economia Política elabora por Marx, para compreender as manifestações nas relações sociais que daí surgem.

Antes de prosseguirmos, cabe salientar que a determinação que conferimos à categoria de trabalho abstrato não é uma centralidade em si, mas sim uma determinação que provém da centralidade do valor que se expressa de forma mais acabada no dinheiro enquanto equivalente universal - e como este precisa se manifestar enquanto forma-mercadoria para realizar seu processo de valorização. Portanto, no percurso analítico do trabalho abstrato, precisamos desvelar mais algumas particularidades da lei do valor.

\section{O valor enquanto troca equivalente: a manifestação do trabalho abstrato}

A universalização do valor, como consequência do modo capitalista de produção, se efetiva na sociedade de maneira complexa. O caráter duplo da mercadoria, expresso no valor e valor de uso, nos leva a desvelar a relação entre as características quantitativa e qualitativa da mercadoria. Além da necessidade objetiva e concreta da mercadoria para manifestar o valor, ou seja, da necessidade qualitativa da mercadoria para manifestar sua grandeza quantitativa enquanto valor, reside também a condição de mensurabilidade numa grandeza objetiva para a troca. Essa mensurabilidade para realizar a troca da mercadoria não poderia se dar sem relativismo se fosse apoiado somente no valor de uso. Isso estabelece o valor, então, como uma condição para uma troca mensurável das mercadorias expresso na sua grandeza quantitativa.

Desta forma, a consumação do valor pode se efetuar numa troca de mercadorias equivalentes de maneira quantitativa, entretanto, na sociedade capitalista a forma mais acabada da realização do valor se encontra expressa no dinheiro. Desse processo se depreende que esta mercadoria específica, o dinheiro, como valor de uso específico é a forma equivalente universal que tem como utilidade a troca, isto é, seu valor de uso é operar enquanto valor de troca. Consequentemente, não é a existência do dinheiro que pressupõe a mercadoria, mas o inverso: a condição de existência da mercadoria que cria a existência do dinheiro. Mas, a relação estabelecida 
entre dinheiro enquanto forma de equivalente e as mercadorias faz com que o primeiro funcione como "[...] modo de existência universal, [e] a mercadoria como seu modo de existência particular, por assim dizer, disfarçado" (MARX, 2017a, p. 229).

O dinheiro, enquanto particularidade da forma-mercadoria que irá se explicitar na forma-dinheiro de maneira universal estabelece-se, assim, como o mediador da troca de mercadorias. Será, portanto, a forma mais acabada do valor e da mercadoria. Embora a mudança seja apenas de forma no que concerne ao valor e à mercadoria, frente a presença do dinheiro, essa distinção é fundamental para compreendermos a perda do caráter útil do trabalho como determinação primordial deste, dando lugar ao trabalho abstrato enquanto expressão materializada do trabalho no modo capitalista de produção.

Somente com o dinheiro, enquanto forma equivalente universal, o valor consegue se generalizar. Como resultado, o trabalho se abstrai da sua especificidade de trabalho produtor de valores de uso (de ser trabalho concreto e útil) e transforma-se, em trabalho especificamente produtor de valor - nesse caso, o valor equipara e equivale pela forma-dinheiro todas as mercadorias, sendo todas, portanto, frutos objetivados do trabalho abstrato.

Portanto, ao se abstrair o caráter útil dos produtos, não estamos fazendo desaparecer o caráter útil do trabalho neles contido, bem como, as suas distintas formas concretas destes trabalhos, entretanto, os produtos se reduzem "[...] a trabalho humano igual, a trabalho humano abstrato". (MARX, 2017a, p. 116). Sobre o caráter equivalente do valor e seu efeito no trabalho enquanto produção de mercadorias, Marx afirma o mesmo raciocínio que tomamos no seguinte trecho:

Quando o casaco é equiparado ao linho como coisa de valor, o trabalho nele contido é equiparado com o trabalho contido no linho. Ora, a alfaiataria que faz o casaco é um tipo de trabalho concreto diferente da tecelagem que faz o linho. Mas a equiparação com a tecelagem reduz a alfaiataria, de fato, àquilo que é realmente igual nos dois trabalhos, a seu caráter comum de trabalho humano. Por esse desvio, diz-se, então, que também a tecelagem, na medida em que tece valor, não possui nenhuma característica que a diferencie da alfaiataria, e é, portanto, trabalho humano abstrato. Somente a expressão de equivalência de diferentes tipos de mercadoria evidencia o caráter específico do trabalho criador de valor, ao reduzir os diversos trabalhos contidos nas diversas mercadorias àquilo que lhes é comum: o trabalho humano em geral. (MARX, 2017a, p. 127-8).

Diante disso, temos que é a manifestação do valor enquanto troca de mercadorias, mediado pela formadinheiro, que traça o caminho do trabalho humano para o enveredado caminho do trabalho humano abstrato. Cabe destacar que:

[...] [as] mercadorias são todas elas expressão de tempo de trabalho objetivado, isto é, nelas materializado. Igualmente, o dinheiro é também expressão de um certo quantum de trabalho passado, de uma soma dada de valor. Nesse sentido, a troca de dinheiro por mercadoria é uma troca de quanta objetivados de trabalho. Troca-se trabalho objetivado por trabalho objetivado. (TEIXEIRA, 1995, p 112)

O efeito que o dinheiro e sua forma ocasiona nas relações sociais de produção infere uma lógica mercantilista de venda e troca em todos os poros. A forma-dinheiro chega até mesmo a mistificar as determinações do valor e produção ${ }^{7}$, lhe dando a aparência de uma força autônoma que confere valor às coisas e não a relação inversa que seria a correta.

O processo de constituição do dinheiro como equivalente universal concreto desnuda o caráter enigmático da forma-dinheiro, por este motivo o dinheiro relaciona-se diretamente ao fetichismo da mercadoria.

O caráter universal da forma-dinheiro, como manifestação da forma-mercadoria, se materializa como valor que tudo pode comprar, pois ela

[...] permite não apenas a possibilidade de uma incongruência quantitativa entre grandeza de valor e preço, isto é, entre a grandeza de valor e sua própria expressão monetária, mas pode abrigar uma contradição qualitativa, de modo que o preço deixe absolutamente de ser expressão de valor, embora o dinheiro não seja mais do que a forma de valor das mercadorias. Assim, coisas que em si mesmas não são mercadorias, como a consciência, a honra etc. podem ser compradas de seus possuidores com dinheiro e, mediante seu preço, assumir a forma-mercadoria, de modo que uma coisa pode formalmente ter um preço mesmo sem ter valor. (MARX, 2017a, p. 177, grifo nosso). 
Assim, a mercadoria se despe de sua forma concreta enquanto manifestação do valor para se exteriorizar enquanto expressão do preço ${ }^{8}$ (que é a expressão fenomênica do valor). A forma-dinheiro tem o papel determinante na atuação de indiferenciação do valor e, consequentemente, do trabalho concreto ${ }^{9}$. Portanto, o dinheiro é a forma mais acabada do valor e a figura central mistificada para o processo de valorização que se alicerça no trabalho indiferenciado enquanto produtor de valores de uso, isto é, a:

[...] forma universal de manifestação do trabalho humano como tal. Assim, o trabalho objetivado no valor das mercadorias não é expresso apenas negativamente como trabalho no qual são abstraídas todas as formas concretas e propriedades úteis dos trabalhos efetivos. Sua própria natureza positiva se põe em destaque: ela se encontra na redução de todos os trabalhos efetivos à sua característica comum de trabalho humano; ao dispêndio de força humana de trabalho. (MARX, 2017a, p. 142-3).

Frente a isso, tampouco significa o desaparecimento das categorias ontológicas ligadas ao trabalho. $\mathrm{O}$ trabalho abstrato apenas se manifesta como determinação destacada do trabalho concreto, da mesma forma que o valor para a produção capitalista se apresenta como determinação destacada do valor de uso. A relação estabelecida entre todos os elementos presentes é uma relação dialética, como um reflexo do próprio duplo caráter da mercadoria enquanto substância de valor e medida de grandeza.

O corpo da mercadoria que serve de equivalente vale sempre como incorporação de trabalho humano abstrato e é sempre o produto de um determinado trabalho útil, concreto. Esse trabalho concreto se torna, assim, expressão do trabalho humano abstrato. Se o casaco, por exemplo, é considerado mera efetivação [Verwirklichung], então a alfaiataria, que de fato nele se efetiva, é considerada mera forma de efetivação de trabalho humano abstrato. Na expressão de valor do linho, a utilidade da alfaiataria não consiste em fazer roupas, logo, também pessoas, mas sim em fazer um corpo que reconhecemos como valor e, portanto, como geleia de trabalho, que não se diferencia em nada do trabalho objetivado no valor do linho. Para realizar tal espelho de valor, a própria alfaiataria não tem de espelhar senão sua qualidade abstrata de ser trabalho humano. (MARX, 2017a, p. 134).

Mesmo com a expressão monetária ganhando sua aparência autonomizada da mercadoria, ela não deixa de ser a manifestação concreta da relação entre a mercadoria e seu valor. A unidade da contradição entre valor de uso e valor expressa na mercadoria, também não deixa de ser um reflexo do duplo caráter do trabalho enquanto trabalho humano concreto e trabalho humano abstrato, isto é, o trabalho em seu sentido ontológico e o trabalho na sua manifestação fenomênica ${ }^{10}$. Lefebvre (2020, p. 161-2), descreve bem essa relação categorial:

Estas categorias dialéticas (e a realidade que lhes corresponde e que elas refletem) constituem, portanto, um todo (uma totalidade). Mas não se confundem, não são iguais simultaneamente, sob o mesmo aspecto. Num momento determinado, é a lei (ou a procura da lei) que importa. Noutro momento, é a riqueza ilimitada da vida, da experiência, dos fenômenos... [...] Assim, o "mundo" desdobra-se necessariamente para e face ao conhecimento humano: abstrato e concreto, pensamento e realidade, conceito e dado imediato, fenômeno e lei, essência e aparência, determinação precisa e devir (transitório)... Mas estes dois "mundos" são um só. Cada um deles constitui um Todo; os dois constituem a totalidade (o universo), isto é, o movimento universal, que o nosso pensamento apreende em tal ou tal grau de profundidade. (grifo do autor).

Nesse sentido dialético é que podemos desvelar a verdadeira essência do capital e seu caráter nas relações sociais. O efeito negativo do trabalho abstrato para a condição de existência do ser social não deixa de ser uma condição do efeito negativo da forma-dinheiro e, por conseguinte, do valor. Toda essa caracterização negativa que se destaca no mundo dos homens tem por fundo sua base ontológica de operação, de tal maneira que em oposição ao trabalho abstrato existe em sua base a especificidade de trabalho concreto, assim como o valor precisa da substância de valor para se materializar, ou seja, o valor de uso.

A exposição dialética da operacionalização das categorias da Crítica da Economia Política se dá apenas porque sua manifestação enquanto fato da realidade é dialética. Sem sombra de dúvidas, isso infere uma visão revolucionária de enxergar a realidade econômica.

Vemos, então, que categoria em Marx tem um sentido dialético, que busca compreender a realidade e não enquadrá-la. Nas palavras deste autor: "Não se trata, aqui, de definições às quais as coisas são subsumidas. 
Trata-se de funções determinadas, que se expressam em categorias determinadas.” (MARX, 2014, p. 316). A contradição, portanto, atua como forma inerente da realidade econômica em que o ser social se encontra inserido.

É nesta forma que compreendemos o processo de trabalho que se encontra abstraído e subsumido pelo processo de valorização:

No processo de trabalho considerado em si, operário emprega os meios de produção. No processo de trabalho que é simultaneamente processo capitalista de produção, os meios de produção empregam o operário, de tal sorte que o trabalho só aparece como um meio graças ao qual determinada quantidade de valor, ou seja, determinada massa de trabalho objetivado, suga trabalho vivo para se conservar e se incrementar. O processo de trabalho aparece assim como processo de autovalorização (por intermédio do trabalho vivo) do trabalho objetivado. O capital emprega o operário, não é o operário que emprega o capital, e só coisas que empregam o operário e que por conseguinte têm no capitalista a sua personificação, a sua consciência e a sua vontade própria, são capital. Na medida em que o processo de trabalho não é mais do que o meio e a forma real do processo de valorização, na medida pois em que é um processo que consiste em objetivar em mercadorias - afora o trabalho que estava objetivado no salário - um excedente de trabalho não pago, uma mais-valia, isto é, produzir mais-valia, nessa medida, o ponto de partida de todo este processo é a troca de trabalho objetivado por trabalho vivo, a troca de menos trabalho objetivado por mais trabalho vivo. [...] trocam-se equivalentes, quantas iguais de trabalho objetivado, embora um quantum esteja objetivado numa coisa e o outro numa pessoa viva. [...] se troca mais trabalho em forma viva do que se tinha gasto em sua forma objetivada. [...] mais trabalho vivo por menos trabalho objetivado corresponde à lei da troca de mercadorias. (MARX, 2004, p.75-76, grifos do autor).

Sendo assim, é no processo de valorização que o trabalho abstrato se manifesta enquanto tal, bem como, é neste que a produção para outrem na propriedade privada é pressuposto elementar, na qual as coisas parecem dominar os homens e não os homens que dominam as coisas. Aparece, portanto, no aspecto fenomênico uma realidade inversa, pois, a relação social entre os homens assume "[...] a forma fantasmagórica de uma relação entre coisas" (MARX, 2017a, p. 147). Essa aparência é resultado da própria forma-mercadoria, da relação especificamente capitalista que se alicerça na propriedade privada e na luta de classes, uma vez que o trabalho como objetivação e exteriorização humanas é colocado em sua característica abstraída, de trabalho indiferenciado que embrutece o trabalhador.

O trabalho em seu caráter abstrato carrega a contraditoriedade imanente do modo de produção capitalista, que se encontra exposto no gérmen da mercadoria e suas mudanças de forma no processo de valorização ${ }^{11}$. Assim, a única mercadoria especial capaz de gerar valor, a força de trabalho, encontra-se subsumida ao capital e sua lógica. A capacidade de riqueza, aliás, encontra-se exatamente na luta de classes, na compra e venda da força de trabalho através da objetivação pelo trabalho abstrato no processo de valorização desta última. Marx (2004, p. 131), pontua essa questão da seguinte forma:

As nossas capacidades são a nossa única riqueza original. Por isso, a capacidade de trabalho não é uma riqueza. O trabalho produz todas as demais riquezas, ou, o mesmo é dizer, produz riqueza para todos os demais, exceto para si próprio, e ele próprio não é uma riqueza mas apenas o seu produto. Todo o trabalho bem dirigido é produtivo; isto é, todo o trabalho produtivo, todo o trabalho que produz um lucro para o capitalista, está bem dirigido.

Ou seja, a riqueza da sociedade capitalista encontra-se justamente na negação da positividade do trabalho, contrapondo a capacidade de trabalho de se exteriorizar para além do valor e do capital ${ }^{12}$. As implicações de valorização e de consumação do capital só podem ocorrer nessa relação com o trabalho abstrato. O fetichismo que daí provém é apenas uma manifestação de como está posta a consciência real dos homens sobre o processo, que tende a atuar de maneira imediata sobre as coisas e, assim, ocultar as reais determinações concretas. Somente nesse invólucro abstraído de sua característica mais dinâmica e essencial enquanto trabalho humano concreto é que os homens conseguem se exteriorizar e se relacionar. Kosik (1976, p. 74-5), em sua obra Dialética do Concreto, consegue sintetizar essa implicação da seguinte forma: 
Pelo simples fato de existir, o homem é um ser social, que não só é sempre fisgado nas malhas das relações sociais, mas sempre age, pensa, sente como um sujeito social; e isto antes ainda de tomar consciência de tal realidade ou até mesmo para dela se dar conta. [...] O homem é antes de tudo aquilo que o seu mundo é. Este ser que não lhe é próprio determina a sua consciência e lhe dita o modo de interpretar a sua própria existência. O sujeito do indivíduo é, em primeira instância e na maioria das vezes, um sujeito que não lhe pertence e isto tanto na forma da falsa individualidade (falso eu), como da falsa coletividade (o nós fetichizado). [...] O sujeito já é constitucionalmente impregnado de objetividade, que é objetivação da praxis humana. O indivíduo pode ser a tal ponto absorvido pela objetividade, pelo mundo da manipulação e da fadiga, que o seu sujeito se perde nessa mesma objetividade e assim a objetividade se apresenta como sujeito real, ainda que mistificado. (grifo do autor).

É preciso notar que Marx tem consciência de tal contradição posta pela produção capitalista, e não é casual que as categorias exploradas por ele ganhem sua efetividade dialética nesse processo. Cabe frisar, que não é uma escolha metodológica, uma vez que o método de Marx nada mais é do que a transposição ideal da materialidade por meio da abstração.

Essa relação parece estar presente nas categorias de capital variável e capital constante, em que sua efetivação enquanto categoria só tem validade no capital produtivo, isto é, no processo de valorização. Tanto o é assim que nas análises de circulação do capital, as determinações de capital constante e variável tomam a forma singular de capital fixo e capital circulante, que perdem a especificidade laboral que é colocada no processo de produção. Disso decorre que tal percurso categorial se dá porque a efetivação do valor e do capital estão manifestados de forma negativa no trabalho humano concreto pela propriedade privada dos meios de produção.

A produção e a circulação, embora ocorram de maneira unitária, estão separadas em sua forma na maneira em que consolidam a efetivação do valor. Portanto, compreende-se o motivo da produção se dar de maneira social, mas sua apropriação ser privada, pois, esta é a maneira de união das contradições do modo de produção capitalista. ${ }^{13}$

\section{Considerações Finais}

A determinação categorial do trabalho humano enquanto trabalho abstrato, perpassa por todas as demais categorias que procuram entender o modo de produção capitalista, pois estas estão centralizadas no valor. É a partir dele enquanto manifestação da exteriorização humana no modo de produção capitalista que conseguimos entender as expressões presentes na realidade deste modo de produção específico. O desenvolvimento humano enquanto um complexo de complexos tem no trabalho humano sua representação abstrata para a efetivação do capital.

O átomo elementar da riqueza na sociedade capitalista, a mercadoria, nos mostra como ela pode dinamizar e fetichizar por suas formas, as relações existentes na realidade multifacetada e interconexa da totalidade. A mercadoria é, portanto, a singularidade da totalidade capitalista, que manifesta suas múltiplas determinações, pois, cada uma contém suas particularidades. $O$ trabalho abstrato carrega a contraditoriedade inerente do modo de produção capitalista, que subsume o trabalho ao capital; o trabalho morto sobre o trabalho vivo; que aliena o ser de suas possíveis exteriorizações concretas.

O devir da lógica do capital, colocada sobre a causalidade do trabalho abstrato, é o devir do empobrecimento humano pari passu a riqueza e efetivação do capital. Isso nos ajuda a entender as ações humanas na sua conexão social com o mundo, cada vez mais alienadas e alienantes, se expressando enquanto relações de dominação, exploração, opressão e degradação de homens e mulheres que laboram diariamente em troca de uma soma monetária para a reprodução de sua vida.

\section{Referências}

GIL, A. C. Método e Técnicas de Pesquisa Social. São Paulo: Atlas, 1987.

KONDER, L. O Futuro da Filosofia da Práxis: o pensamento de Marx no século XXI. Rio de Janeiro: Paz e Terra, 1992.

KOSIK, K. A Dialética do Concreto. Rio de Janeiro: Paz e Terra, 1976. 
LEFEBVRE, H. O Pensamento de Lênin. São Paulo: LavraPalavra Editorial, 2020.

LENIN, V. I. Imperialismo, Estágio Superior do Capitalismo. São Paulo: Expressão Popular, 2012.

LUKÁCS, G. Para uma Ontologia do Ser Social II. São Paulo: Boitempo, 2013.

MARX, K. Capítulo VI inédito de O Capital: resultados do processo de produção imediata. São Paulo: Centauro, 2004.

MARX, K. O Capital: Crítica da Economia Política, Livro I, O Processo de Produção do Capital. São Paulo: Boitempo, 2017a.

MARX, K. O Capital: Crítica da Economia Política, Livro II, O Processo de Circulação do Capital. São Paulo: Boitempo, 2014.

MARX, K. O Capital: Crítica da Economia Política, Livro III, O Processo Global da Produção Capitalista. São Paulo: Boitempo, 2017b

OSÓRIO, J. O Estado no Centro da Mundialização: a sociedade civil e o tema do poder. São Paulo: Expressão Popular, 2019.

TEIXEIRA, F. J. Pensando com Marx: uma leitura crítico-comentada de O capital. São Paulo: Editora Ensaio, 1995.

\section{Notas}

1 "A riqueza das sociedades onde reina o modo de produção capitalista aparece [erscheint] como uma enorme coleção de mercadorias, e a mercadoria individual, por sua vez, aparece como forma elementar" (MARX, 2017a, p. 113).

2 Gil (1987) classifica pesquisa bibliográfica como um tipo de pesquisa "desenvolvido a partir de material já elaborado, constituído principalmente de livros e artigos científicos". (GIL, 1987, p. 71), ou seja, materiais submetidos a tratamentos e revisões.

3 Tomamos como pressuposto neste artigo a utilização das categorias valor e valor de uso. Não se trata de um abandono da categoria de valor de troca, mas apenas o entendimento que "[...] o valor de troca não pode ser mais do que o modo de expressão, a "forma de manifestação" [Erscheinungsform] de um conteúdo que dele pode ser distinguido" (MARX, 2017a, p. 115). Partimos, então, do entendimento do valor enquanto categoria que já compreende o valor de troca, e que pode desvelar as determinações do processo de produção e não apenas de circulação.

4 Na primeira edição d'O Capital' Marx trabalha com a categoria substância de valor e grandeza de valor de maneira mais detalhada, sendo a primeira o corpo de manifestação do valor e a segunda a forma do valor em si. Sobre a substância do valor ele afirma que "[...] é o trabalho", e prossegue: "Conhecemos sua medida de grandeza. Ela é o tempo de trabalho. Resta analisar sua forma, que fixa o valor precisamente como valor de troca." (MARX, 2017a, p. 118, grifo do autor).

5 "Por força de trabalho ou capacidade de trabalho entendemos o conjunto das capacidades físicas e mentais que existem na corporeidade [Leiblichkeit], na personalidade viva de um homem e que ele põe em movimento sempre que produz valores de uso de qualquer tipo" (MARX, 2017a, p. 242).

6 Leandro Konder (1992, p. 136), numa mesma perspectiva, é preciso quando chama tal movimento de "mercantilização da vida".

7 "O nome de algo é totalmente exterior à sua natureza. Não sei nada de um homem quando sei apenas que ele se chama Jacó. Do mesmo modo, nas denominações monetárias libra, táler, franco, ducado etc. desaparece todo sinal da relação de valor. A confusão sobre o sentido oculto desses símbolos cabalísticos é tanto maior porque as denominações monetárias expressam o valor das mercadorias e, ao mesmo tempo, partes alíquotas de um peso metálico, do padrão monetário. Por outro lado, é necessário que o valor, em contraste com os variados corpos do mundo das mercadorias, desenvolva-se nessa forma material, desprovida de conceito, mas também simplesmente social" (MARX, 2017a, p. 175, grifo nosso).

8 A diferença não apenas categorial, mas concreta entre valor e preço (representado na forma-mercadoria e na forma-dinheiro) exigiria uma exposição que excede os limites deste trabalho. Contudo, o enfoque analítico que queremos explicitar é como a universalização do dinheiro opera uma inflexão no caráter do valor e das relações sociais de produção.

9 Embora contenha inúmeros trechos em que Marx aborda a temática escolhida, a fim de não nos estendermos em inúmeras citações, cabe ainda esta última exposição: "Em sua figura de valor, a mercadoria se despoja de todo traço de seu valor de uso naturalespontâneo e do trabalho útil particular ao qual ela deve sua origem, a fim de se crisalidar na materialidade social e uniforme do trabalho humano indiferenciado. Não se percebe no dinheiro de que qualidade é a mercadoria que foi nele transformada. Em sua forma-dinheiro, uma mercadoria tem a mesma aparência que a outra. Por isso, o dinheiro pode ser lixo, embora lixo não seja dinheiro" (MARX, 2017a, p. 183).

10 "Todo trabalho é, por um lado, dispêndio de força humana de trabalho em sentido fisiológico, e graças a essa sua propriedade de trabalho humano igual ou abstrato ele gera o valor das mercadorias. Por outro lado, todo trabalho é dispêndio de força humana de trabalho numa forma específica, determinada à realização de um fim, e, nessa qualidade de trabalho concreto e útil, ele produz valores de uso" (MARX, 2017a, p. 124).

11 Para compreender as mudanças de forma da mercadoria e do capital cf. Marx (2014), em especial a 'Seção I-As metamorfoses do capital e seu ciclo'.

12 Osório (2019, p. 146), tratando a questão de maneira breve pontua incisivamente acerca da capacidade subjetiva da força de trabalho: "A força de trabalho está na corporeidade viva do trabalhador (músculos, cérebro, sistema nervoso, esqueleto, coração, 
pulmões etc.). Não há como separar uma coisa da outra. Portanto, quando o trabalhador vende sua força de trabalho - o capital não apenas recebe aquela mercadoria, mas também a corporeidade total do trabalhador. E tudo que acontece com essa força de trabalho - trabalhando em extenuantes jornadas, intenso trabalho, para não falar das exaustivas horas de deslocamento da casa ao trabalho e vice-versa - incide no trabalhador e em seu corpo (e alma ou espírito)"

13 "Percebe-se que as relações de economia e propriedade privada constituem uma forma que já não correspondem ao conteúdo, uma forma que deve inevitavelmente decompor-se se a sua supressão for adiada artificialmente, que pode permanecer em estado de decomposição durante um período relativamente longo, [...] mas que, de qualquer modo, será inelutavelmente eliminada" (LENIN, 2012, p. 170).

\section{Havana Maria Ribeiro Alves}

havana.ribeiroo@gmail.com

Mestrado em Serviço Social pelo Programa de Pós-graduação em Serviço Social da Universidade Federal de Alagoas (PPGSS/UFAL)

Doutoranda em Serviço Social pelo Programa de Pós-graduação em Serviço Social da Universidade Federal de Santa Catarina (PPGSS/UFSC). Bolsista pela Coordenação de Aperfeiçoamento de Pessoal de Nível Superior (CAPES).

\section{Leandro Nunes}

leccinunes23@hotmail.com

Mestrado em Serviço Social pelo Programa de Pós-graduação em Serviço Social da Universidade Federal de Santa Catarina (PPGSS/UFSC)

Doutorando em Serviço Social pelo Programa de Pós-graduação em Serviço Social da Universidade Federal de Santa Catarina (PPGSS/UFSC). Bolsista pela Fundação de Amparo à Pesquisa e Inovação do Estado de Santa Catarina/Coordenação de Aperfeiçoamento de Pessoal de Nível Superior (FAPESC/CAPES)

\section{Pablo Ramon Diogo}

pablo.rdiogo@gmail.com

Graduando em Serviço Social pelo Departamento de Serviço Social da Universidade Federal de Santa Catarina (DSS/UFSC)

Bolsista pelo Conselho Nacional de Pesquisa e Inovação Tecnológica (CNPq), nível Programa Institucional de Bolsas de Iniciação Científica (PIBIC) da Universidade Federal de Santa Catarina (UFSC)

\section{UFSC}

R. Eng. Agronômico Andrei Cristian Ferreira, s/n - Trindade

Florianópolis - SC

CEP: 88040-900

\section{Agradecimentos}

Não se aplica.

Agência financiadora

Não se aplica.

Contribuições das autoras

O trabalho foi realizado em conjunto por todos os autores envolvidos.

\author{
Aprovação por Comitê de Ética e consentimento para \\ participação \\ Não se aplica. \\ Consentimento para publicação \\ Os autores consentem a publicação. \\ Conflito de interesses \\ Não há conflito de interesses.
}

